\title{
Microstructure of Carbon Fiber and Carbon Reinforced Plastic
}

\author{
N. I. Baurova ${ }^{1}$, Wei Hao ${ }^{2}$, Ouyang Xiao \\ ${ }^{1}$ Department of Manufacture and Repair of Motor Vehicles and Road Cars, Moscow Automobile \\ Road State Technical University (MADI), Moscow, Russia \\ ${ }^{2}$ Department of Material Science and Chemical Engineering, Harbin Engineering University, Harbin, China \\ Email: nbaurova@mail.ru
}

Received August 2013

\begin{abstract}
This study is the investigation of the microstructure of different types of carbon fiber. They were compared with the carbonized and graphitized fibers. Results of structural researches have been presented. It was found that the damage varies from different pollution and the damage of the monofibers. The effect of the pollution of the monofiber was determined.
\end{abstract}

Keywords: Cold Curing Epoxy Matrix; Carbon Fiber; Carbon Reinforced Plastic; Microstructure

\section{Introduction}

The carbon fibers (CF), and also carbon tapes and fabrics are for a long time used in power designs of many types of planes, as in Russia, and in foreign countries, for producing of bearing panels of wings of plumage and fuselages; for producing of coverings of three-layer panels of various types of the antennas working in space; shovels of turbines, nozzle blocks, nasal fairing and many other products. Carbon fibers are also widely applied in producing of various heating elements.

Carbon fibers represent a bunch of the monofibres, whose quantity depends on the carbon fibers brand, can change in very wide limits, from several thousand to ten thousand of pieces. Each monothread represents nanoporous strong substance which possesses unique electrophysical properties that opens new areas of their application, for example, as touch sensors when diagnosing designs in real time [1].

Carbon fibers are received when heating cellulose (poliakrilonitrilny and other types) fibers. It is a difficult process which is carried out for some stages. At the first stage there is an oxidation at temperatures of $200^{\circ} \mathrm{C}$ $325^{\circ} \mathrm{C}$ at which there is the main loss of weight and fiber shrinkage. At the second stage carbonization is carried out at temperatures of $1000^{\circ} \mathrm{C}-1500^{\circ} \mathrm{C}$, then at temperatures of $2500^{\circ} \mathrm{C}-2800^{\circ} \mathrm{C}$ graphitization. Depending on the stage, in which the production process was interrupted, or carbonized fibers with different high durability, or graphitized fibers with the high module of elasticity are received. Simply the model of structure of carbon fiber can be presented in the form of consistently alternating blocks of crystallites which are connected among themselves by amorphous sites [2].

\section{Experimental Process}

In this work the structural researches of four different carbon fibres are conducted with the use of a raster and electronic microscope of Phenom Company.

\section{Results and Discussions}

\subsection{Carbon Mono-Fibres}

The structure of carbon fibers is formed at a carbonization and graphitization stage as a result of course of physical and chemical processes. Process of formation of nanostructure of carbon fiber consists of two stages: at the first stage education from macromolecules of nanostructural educations-microfibrilla takes place. At the second stage, in process of increase in temperature, the macromolecule gradually from the twisted turns in linear and diameter of microfibrilla increases. It occurs because gradually all available in structure swore at functional groups decay with formation of amorphous carbon chains. Between microfibrilla there is time which inevitably arises because of shrinkage of carbon fiber which takes place at all stages of its oxidation (see Figure 1). In the process of temperature increasing the number of covalent communications with which the next microfibrilla gradually connects increases.

Thus, the structure of graphitized carbon fiber is 


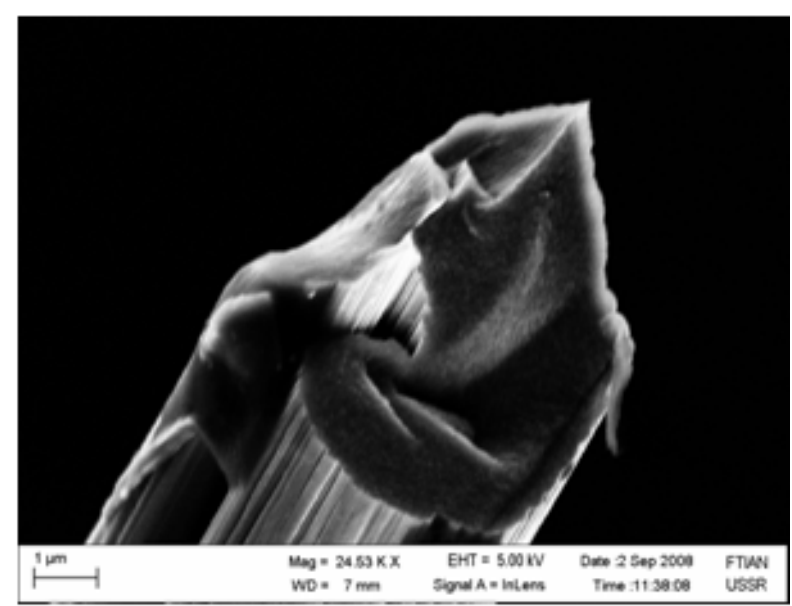

(a)

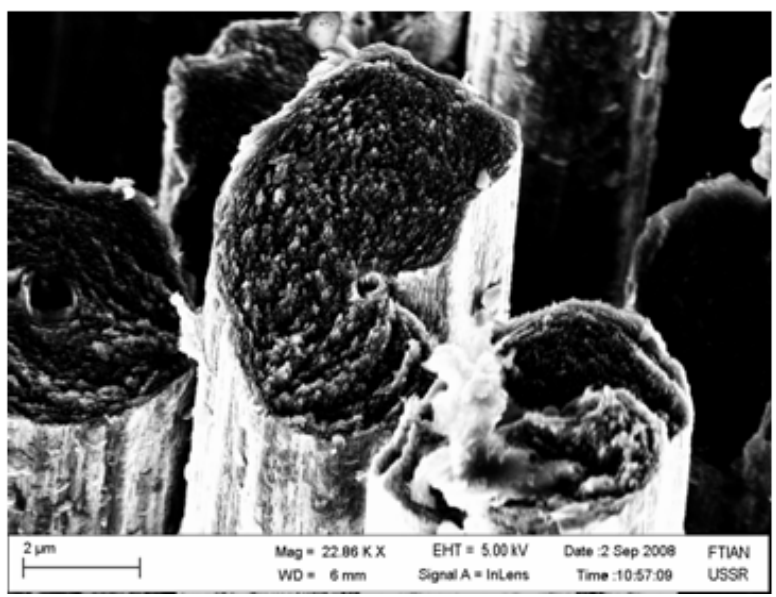

(c)

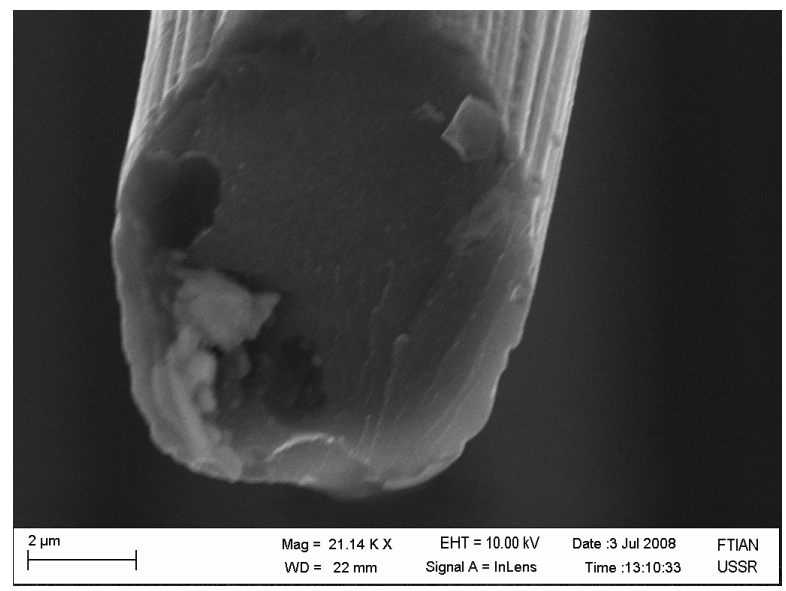

(e)

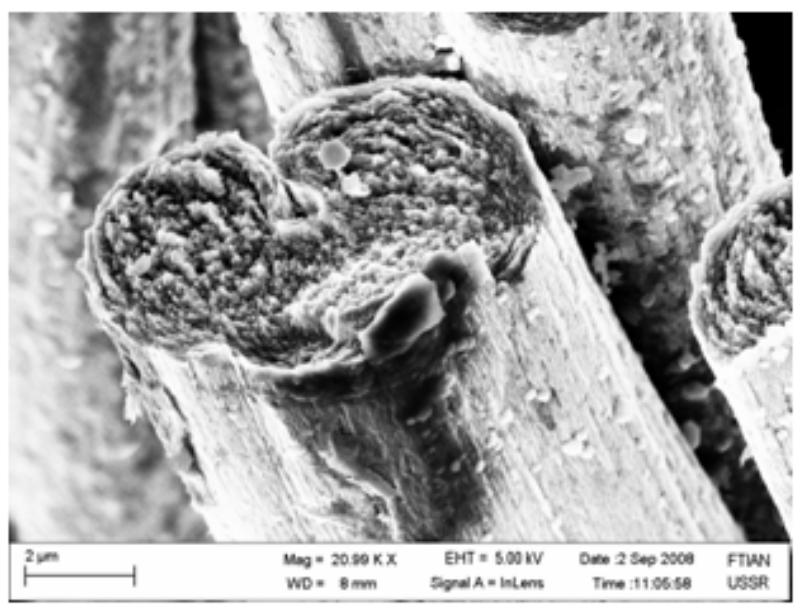

(b)

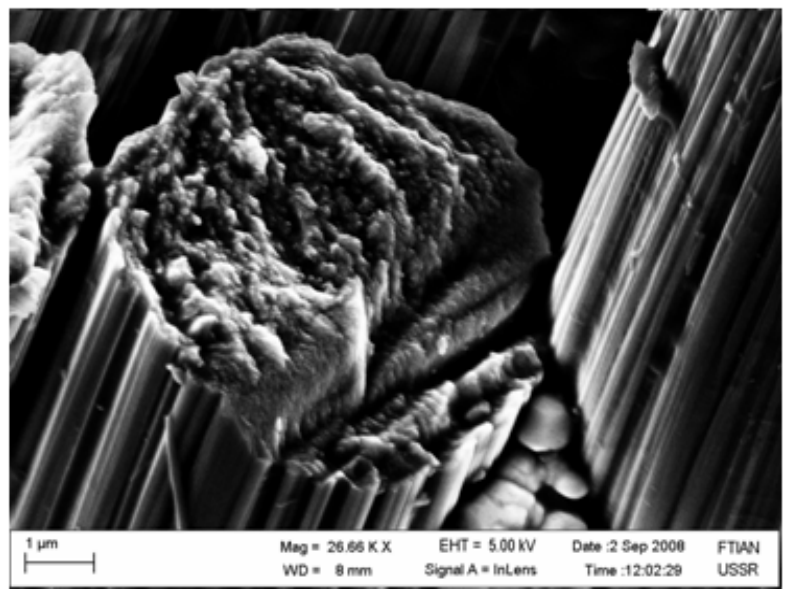

(d)

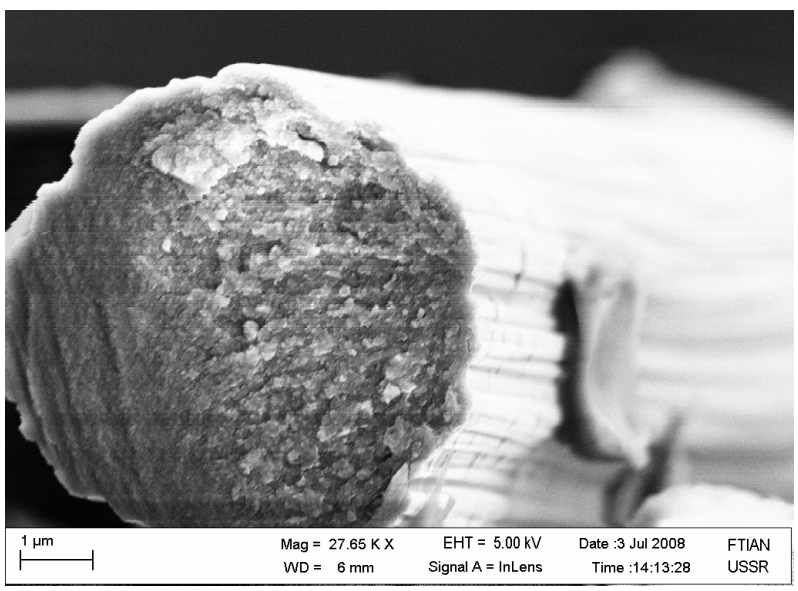

(f)

Figure 1. Structure of a monothread of carbon fiber: (a) Elur; (b), (c) Culon; (d) LU; (e) UKN-P; (f) UKN-2-500.

anisotropic and represents the crystallites condensed among them and the amorphous sites consisting of atoms of carbon (see Figure 1), these sites have respectively dark and light colors. For cars of carbon fibers used at diagnosing the nanostructured axial and ring structure in rela- tion to a fiber axis is characteristic. In the center of fiber the areas, being characterized are located the greatest concentration of tension. At the edges of fiber there are areas with radial orientation. Heat-resistant inclusions significantly differ from the main structure of fiber. 
As a result of the conducted researches it is established that carbonized carbon fibers contain a large amount of impurity which represent not completely remote coke particles of organic polymer (Figure 2). These impurities have essential impact on electrophysical properties of carbon fibers and for this reason carbonized fibers can't be used as sensors when diagnosing metalwork [3].

Graphitized carbon fibers contain the smaller amount of impurities and for this reason possess more stable electrophysical properties. In the longitudinal direction, i.e. parallel to a fiber axis, carbon monofibres have well focused and similar structure that is connected with features of an arrangement of graphite layers.

Diameters of monothreads of carbon fibers in one party are close to each other and make about 10.5 microns. The exact size of a monothread of carbon fibers is

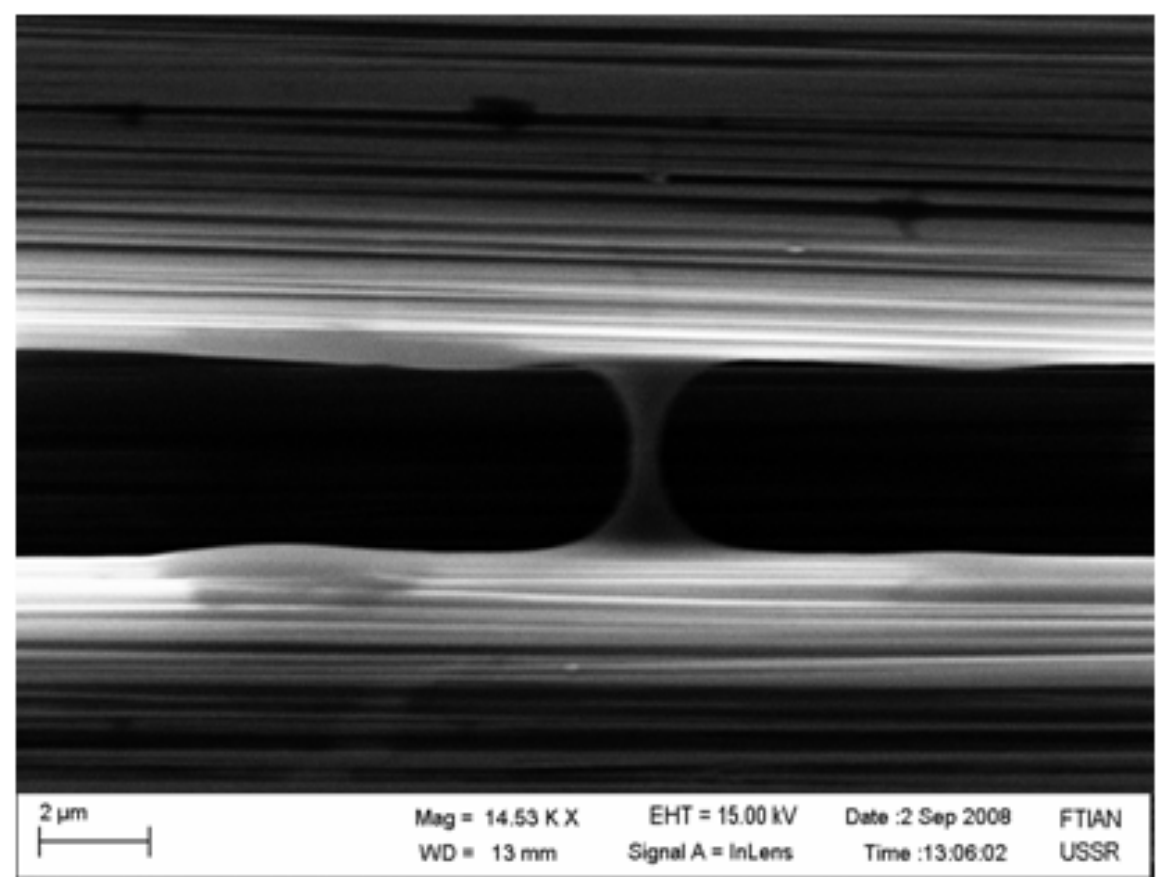

(a)

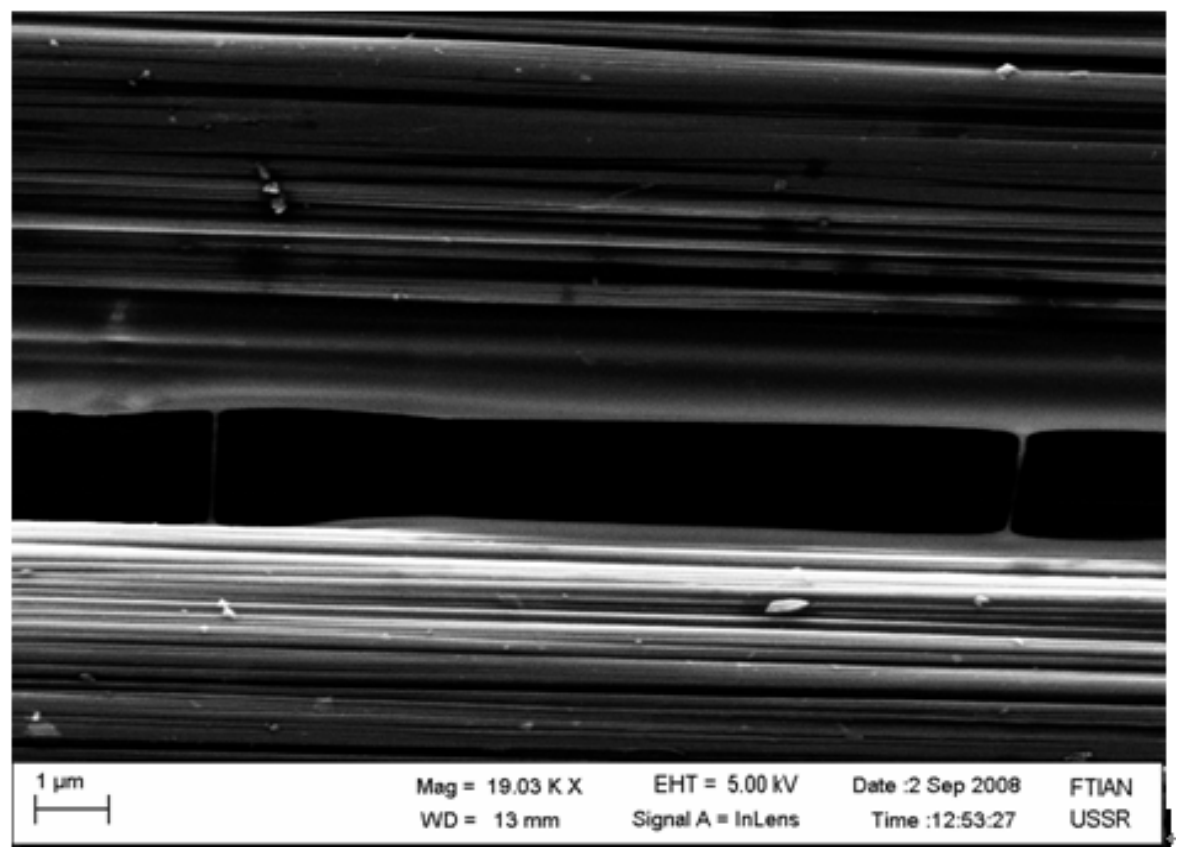

(b)

Figure 2. Appearance of a monothread graphitized (a) Carbonized; (b) Fiber. 
determined directly in microplasticit.

\subsection{Carbon Mono-Fibres Reinforced Epoxy Composite}

For further researches, with use of carbon fibers of the UKN-2500 brand and epoxy binding on the basis of epoksidianovy pitch and an aminny hardener samples of microplastics which after a full cold curing proses at $20^{\circ} \mathrm{C}$ within 24 hours were tested for a gap were made, and surfaces of destruction are investigated on an electronic microscope. Determination of nature of destruction on the basis of which it would be possible to predict durability was the purpose of these researches.

The carried-out structural analysis showed (Figure 3) that adhesive nature of destruction takes place, i.e. the gap occurs accurately on a surface of interphase border a polymeric matrix-carbon fiber. Nature of destruction elastic and black sites on a photo designate those places where took place having dug monothreads together with the binding.

On the basis of results of structural researches carbon fibers it is possible to assume that pollution on the surfaces of monothreads representing particles of coke, completely not removed in the course of graphitization, don't allow to receive strong coupling of fiber and a polymeric matrix and at loadings matrix peeling from fiber takes place.

As recommendations about increase in size of adhesive durability it is possible to suggest touse special finish coats with which it is necessary to process carbon fibers surface before drawing a layer on it binding.

As other recommendation which also will allow increasing durability of adhesive interaction of carbon fibers and epoxy binding, it is necessary to use at carbon fibers impregnation binding with smaller viscosity that will allow reducing significantly thickness of a layer binding between two next monothreads. For reduction of viscosity two various ways can be used. The first-use of the solvent, the second-heating binding before impregnation. At the first way carbon reinforced plastic with the minimum thickness of a layer binding will be received, however they will contain an additional time which will be formed at solvent volatilization in the course of a curing proses. The second way will allow receiving porefree composites, however, thickness of a layer binding will be higher, than when using solution technology.

The received structures of surfaces show that this binding doesn't possess relaxation properties and at submicrolevel, most likely, its multiple cracking takes place.

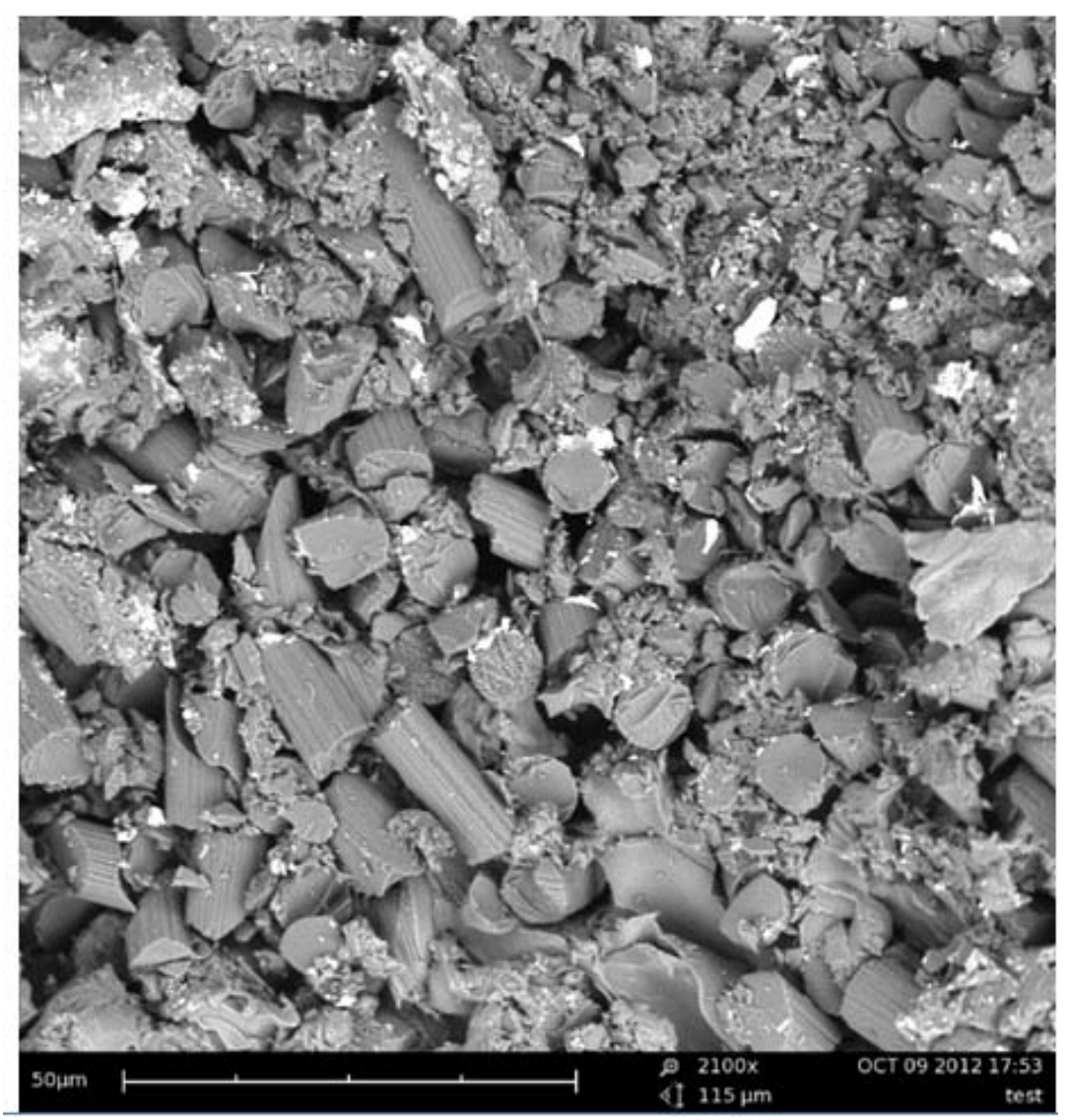

Figure 3. Photo of a surface destruction of carbon reinforced plastic. 
Further at microlevel there is a fast formation of sites where accumulation of defects take place that leads to that at their certain concentration formation of the main crack which, as a rule, in fragile materials develops with a high speed will take place and quickly sprouts, and at the development this crack is capable to cut the next monofibres further.

\section{Conclusion}

The conducted structural researches of carbon fibers and microplastics on their basis showed that used carbon fibers of the UKN-2500 brand has a large amount of initial defects in the form of pollution on all their length that as a result leads to fragile and adhesive destruction of carbon reinforced plastic. Use of data of carbon fibers at production of responsible details from carbon reinforced plastic will demand the additional measures, allowing increasing the size of adhesive durability on interphase zone.

\section{Acknowledgements}

This work was supported by the Chinese international science and technology program (No. 2011DFR50770).

\section{REFERENCES}

[1] V. I. Kostikov, "Constructional Materials on the Basis of Carbon in Modern Equipment-Chelyabinsk: Collection of Scientific Works," Modern Problems of Production and Operation of Carbon Production, 2005, pp. 8-11.

[2] V. A. Zorin and N. I. Baurova, "Influence of External Factors on the Accuracy of Diagnosing of Road-Building Cars with Use of Carbon Fibers," Construction and Road Cars, No. 1, 2009, pp. 50-51.

[3] N. I. Baurova, "Diagnostirovaniye and Repair of Cars about Application Polymeric Materials,” Tekhpoligraftsentr, 2008, 280 p. 